\title{
Fatty Acid-Binding Protein, Intestinal
}

National Cancer Institute

\section{Source}

National Cancer Institute. Fatty Acid-Binding Protein, Intestinal. NCI Thesaurus. Code C29616.

Fatty acid-binding protein, intestinal (132 aa, $\sim 15 \mathrm{kDa}$ ) is encoded by the human FABP2 gene. This protein plays a role in binding to saturated long-chain fatty acids with a high affinity and to unsaturated long-chain fatty acids with less affinity. 